\title{
Idéias para uma sociologia da questão ambiental - teoria social, sociologia ambiental e interdisciplinaridade
}

\section{Ideas for an environmental issues sociology - social theory, environmental sociology and interdisciplinarity}

\author{
Leila da COSTA FERREIRA*
}

\section{RESUMO}

Tendo a sociologia ambiental como centro da abordagem este texto focaliza, de forma analítica, a evolução do envolvimento da ciência social no trato da problemática ambiental. Esta evolução parte de uma análise dos pensadores clássicos da sociologia e vai até o momento presente. Ao tratar da relação entre questão ambiental, ciências sociais e interdisciplinaridade no Brasil, o texto evoca instituições acadêmicas e científicas, bem como a produção intelectual no país, e conclui por constatar que ocorreu uma internalização desta questão nas ciências sociais brasileiras.

Palavras-chave: questão ambiental, sociologia ambiental, interdisciplinaridade, Brasil.

\begin{abstract}
With environmental sociology as its central approach, this text places an analytical focus on the evolution of social science's involvement in addressing the environmental issue. This evolution stems from an analysis of sociology's classical thinkers from the past until the present day. In addressing the relationship between the environmental issue, social sciences, and interdisciplinarity in Brazil, the text brings to the fore academic and scientific institutions as well as the country's intellectual production, and concludes by showing that this issue has become an integral part of social sciences in Brazil.

Key-words: the environmental issue, environmental sociology, interdisciplinarity, Brazil.
\end{abstract}

\footnotetext{
* Doutora em Ciências Sociais e Professora Titular da Unicamp. Presidente da Anppas - Associação Nacional de Pesquisa e Pós-Graduação em Ambiente e Sociedade.leilacf@unicamp.br
} 
COSTA FERREIRA, L. da. Idéias para uma sociologia da questão ambiental...

A sociologia ambiental, enquanto produção científica e acadêmica, emergiu a reboque dos movimentos de contestação social surgidos no início dos anos 60 e da constatação da situação emergencial de degradação dos recursos naturais e do desenvolvimento do industrialismo. O nascimento do movimento na década de 1960 surpreendeu os sociólogos, que naquele momento não dispunham de um corpo teórico ou tradição empírica que os guiasse em direção ao entendimento da relação entre sociedade e natureza. Os pioneiros da sociologia clássica (Durkheim, Marx e Weber) tinham abordado a questão de modo tangencial; além disso, apenas raramente surgiam trabalhos isolados, sem, no entanto, promover uma acumulação considerável de conhecimento que permitisse a criação de um campo teórico. Existem várias hipóteses para o entendimento deste processo.

Entretanto, embora de forma diferenciada segundo países, principalmente a partir dos anos 1960, grupos de sociólogos começaram a dar importância à problemática ambiental e perceber sua relevância e abrangência e este tema passou a ocupar a agenda dos governos, organismos internacionais, movimentos sociais e setores empresariais em todo mundo. Tornou-se evidente que a questão ambiental não era apenas mais um modismo passageiro, nem uma dramatização de militantes ou cientistas radicais.

A sociologia ambiental assume então uma posição significativa para estudar as divergências e conflitos sobre os diferentes usos da natureza (entendida aqui em seu sentido mais amplo, ou seja, tanto o ambiente natural quanto o construído) e as causas e a extensão dos problemas ambientais e os diversos atores envolvidos.

Além disso, a teoria social contemporânea também tem estudado e refletido sobre esta questão como veremos no transcorrer deste artigo.

Neste sentido pretendo discutir esta produção intelectual que desde a década de 1970 até o presente momento vem problematizando a questão ambiental, sugerindo algumas hipóteses deste processo bem como levantar possíveis questionamentos de encaminhamentos.

\section{Influências teóricas que nortearam a análise da produção intelectual na área}

$\mathrm{Na}$ interpretação weberiana depara-se com esferas múltiplas de determinação da ação social. Podemos falar de uma esfera econômica, relacionada aos conteúdos de sentido referentes à produção econômica e ao mercado. De uma esfera social relacionada aos conteúdos de sentido identificados a um ethos social e a concepção de honra (prestígio), ou de uma esfera política relacionada aos conteúdos de sentido referentes às lutas pelo poder. Podemos também falar de uma esfera jurídica, estética, religiosa ou mesmo científica, cada qual relacionada a uma forma específica da ação social e a produção de conteúdos de sentido que lhe são pertinentes.

Neste sentido poderíamos estabelecer aqui as maneiras pelas quais Max Weber (1979) se faz presente nas formulações teóricas propostas por Bourdieu (1980). Como em Weber, a questão dos sentidos, que os homens atribuem as suas condutas é central em Bourdieu. Ao pensar a cultura, ou os sistemas simbólicos, Bourdieu procura sintetizar elementos de diversas orientações teóricas, reconhecendo que estas se repartem em duas vertentes principais: a primeira matriz Kantiana (DURKHEIM, 1995, por exemplo) onde os sistemas sociais são pensados ao mesmo tempo como meios de comunicação (estruturas estruturadas) e como instrumentos de conhecimento e da construção do mundo objetivo (estruturas estruturantes).

A primeira tradição caracteriza-se por tentar compreender como se articulam a partir da elaboração simbólica as formas de consenso. A segunda vertente teria em Marx (1980) e Weber (1979) seus principais expoentes e se caracteriza pelo entendimento dos sistemas simbólicos como instrumentos de dominação.

É desta reflexão sobre estas duas vertentes interpretativas que Bourdieu irá desdobrar os conceitos fundamentais com que opera: o de habitus e o de campo.

A crença nas relações entre produção de conteúdo de sentido e de formas de dominação, bem como a idéia de que os diversos processos por meio dos quais tais conteúdos de sentido se produzem podem configurar esferas dotadas de uma lógica particular, fazem com que o conceito de campo seja tributário em grande medida, da concepção weberiana da autonomia das esferas sociais.

Temos aqui atores que se movimentam por entre configurações de idéias e instituições.

Por um lado, a percepção de um campo de poder, posições que se entrelaçam em um sistema de relações que confere particularidade a cada posição e ao próprio conjunto, que é sempre dinâmico e marcado por disputas.

De outro, a noção de campo intelectual, que ganha autonomia na medida em que crescem o nível de especialização e o status dos produtores de bens simbólicos. 
COSTA FERREIRA, L. da. Idéias para uma sociologia da questão ambiental...

Idéias, práticas, instituições e hábitos configuram um campo.

Neste sentido, Bourdieu (1980) propõe uma teoria da prática na qual as ações sociais são concretamente realizadas pelos indivíduos, mas as chances de efetivá-las se encontram objetivamente estruturadas no interior da sociedade global.

Poderíamos arriscar aqui um breve comentário que se articula com outras influências teóricas que subsidiaram a tentativa de uma sociologia da questão ambiental.

A criatividade sociológica supõe, ao mesmo tempo, um corte com o senso comum e uma elaboração permanente e audaciosa de novas hipóteses. Como bem sabemos as grandes criações científicas não se reduzem "nem ao grito da revolta" (a simples ideologia), "nem ao rigor das construções científicas". Evidentemente, no interior da obra de um autor existe um grau diversificado de coeficiente ideológico. O trabalho intelectual nutre-se de uma dimensão ambivalente (ambivalência não é sinônimo de ambigüidade): o rigor e o controle científico e uma vinculação visceral às coisas do mundo (ORTIZ, 2002).

Neste sentido, as dificuldades para conhecer a verdade, (de que nos falava Bertolt Brecht e salientada por HABERMAS, 1987), é um problema de que as ciências sociais estão obrigadas a se colocar neste século, não por uma questão de calendário, mas da consciência crítica da dificuldade dos saberes disciplinares diante da sociedade complexa.

A primeira diz respeito à relação do investigador com a investigação. No início do século, Max Weber resumiu a trajetória do pensamento moderno chamando-lhe "desencantamento do mundo". A expressão limitava-se a descrever um processo que de fato se desenvolvera ao longo de centenas de anos. Prigogine e Stengers (1996) apelaram a um "reencantamento do mundo". O conceito de "desencantamento do mundo" representou a busca de um conhecimento objetivo, liberto de sabedorias ou ideologias e/ou aceitas. Tal exigência constitui um passo fundamental no sentido de libertar a atividade intelectual de pressões externas e da mitologia, e continua manter-se válida. Não temos, portanto, o menor desejo de fazer retroceder o pêndulo e de novo nos encontrarmos na difícil situação de que o desencantamento do mundo nos procurou salvar.

$\mathrm{O}$ apelo no sentido de um "reencantamento do mundo" é de natureza diferente. Não se trata de um desejo de mistificação. Trata-se, antes, de um apelo ao desmantelamento das fronteiras artificiais existentes entre os seres humanos e a natureza, ao reconhecimento de que ambos fazem parte de um universo único, atravessado pela flecha do tempo. Transpor o reencantamento do mundo para uma prática razoável e eficaz não é tarefa fácil.

Neste sentido, se o investigador não pode ser "neutro" e se o tempo e o espaço são variáveis internas da análise, temos como conseqüência necessária da análise que a tarefa de reestruturação das ciências sociais tem de resultar da interação de estudiosos provenientes das mais diversas paragens e perspectivas, e que esta interação seja algo real e não mera cortesia para mascarar a imposição das concepções de apenas alguns setores da comunidade científica (COMISSÃo GULBENKIAN, 1996).

É certo que estamos a assistir ao surgimento de grupos específicos de cientistas sociais (e mesmo de outros que não o são), unidos por interesses ou áreas temáticas como a Questão Ambiental.

Neste sentido, podemos refletir onde estariam as oportunidades de experimentação criativa. Podemos aqui apenas apontar algumas, situações em pontos muito diferentes na produção intelectual da área de interface entre Ambiente e Sociedade.

A discussão sobre interdisciplinaridade é objeto de constantes controvérsias, não havendo consenso sobre a mesma, o que se pode dizer sobre este debate é que existem, grosso modo, duas visões diferenciadas: a primeira delas aproxima o diálogo entre disciplinas científicas, no intuito de ampliar a explicação dos objetos de conhecimento disciplinares como no caso da sociologia ambiental onde se busca interagir teoricamente em alguns temas de convergência.

Uma segunda visão sobre a construção interdisciplinar restringe-se mais ao campo da pesquisa temática, opondo-se à visão das assimilações progressivas entre disciplinas. Esta visão reconhece a especificidade disciplinar, mas adota uma espécie de colaboração deliberada dos saberes disciplinares sobre temas previamente definidos (FLORIANI, 2000).

Neste sentido, podemos apontar algumas hipóteses que nortearam a análise da produção intelectual no Brasil. Em primeiro lugar, tudo indica que a ênfase nessa área transversal migrou da busca inglória por um ator preferencial de mudança social na ordem econômica ou ambiental para uma questão genérica delineada em torno das preocupações com a dimensão humana das mudanças ambientais, independente de juízos de valor sobre elas. Atualmente, essa questão é decomposta em outras derivadas que dizem 
COSTA FERREIRA, L. da. Idéias para uma sociologia da questão ambiental...

respeito à governabilidade e às orientações sociais e culturais ou normativas para a resolução de problemas universalmente reconhecidos e considerados politicamente pertinentes. Nessa linha as discussões e reflexões das diferentes vertentes citadas no conteúdo deste trabalho centram-se em objetos que se inter-relacionam para dar conta de problemas como normatividade, institucionalidade e a emergência de novas instituições sociais na área ambiental.

Em segundo lugar e não menos importante está o fato que tanto a produção na área no seu período de formação (nos anos 1960) como a posterior, bem como a discussão sobre a interdisciplinaridade, acaba influenciando e sendo influenciada pela teoria social contemporânea.

Existem alguns autores (LEIS, 2000, por exemplo) que argumentam que no caso brasileiro estaríamos, na maior parte das vezes, não desenvolvendo perspectivas teóricas em relação ao tema, mas respondendo a uma demanda desenfreada da sociedade civil em relação aos graves problemas ambientais brasileiros.

No entanto as discussões teóricas e metodológicas desenvolvidas em artigos anteriores (FERREIRA, 2001; FERREIRA e FERREIRA, 2002) tentam mostrar que no caso brasileiro, há também setores da comunidade acadêmica influenciados tanto pelas correntes ligadas à modernização reflexiva (teoria do risco e modernização ecológica), como pelas perspectivas construtivistas.

\section{Sociologia ambiental: surgimento e institucionalização}

A sociologia ambiental, como produção científica e acadêmica, emergiu a reboque dos movimentos de contestação social surgidos no início dos anos de 1960 e da constatação da situação emergencial de degradação dos recursos naturais e do desenvolvimento do industrialismo (PAEHLKE, 1989; MACCORMICK, 1992; ECKERSLEY, 1995). Talvez porque o nascimento do ambientalismo na década de 1960 tenha surpreendido os sociólogos, que, naquele momento, não dispunham de um corpo teórico ou tradição de pesquisa empírica que os guiasse em direção ao entendimento da relação entre sociedade e natureza (VIOLA e LEIS, 1992).

Os pioneiros da sociologia clássica, Durkheim, Marx e Weber tinham abordado a questão de modo tangencial; além disso, apenas raramente surgiam trabalhos isolados na área de sociologia rural, sem, no entanto promover uma acumulação considerável de conhecimentos que permitisse a criação de um campo ou subcampo teórico.

Hannigan (1997) acredita em duas explicações para o fato dos sociólogos marginalizarem a questão ambiental em seus empreendimentos teóricos. Uma delas se refere às falhas do determinismo geográfico e biológico, e sua visão conservadora sobre o entendimento das mudanças e conflitos sociais; a outra diz respeito ao próprio pensamento vigente que, em meados do século XX, enfatizava a literatura sociológica da modernização. O que atualmente é identificado como preocupação ambiental seria visto como atraso e obstáculo ao desenvolvimento, ao progresso. Certamente havia críticos ao paradigma desenvolvimentista, como os sociólogos marxistas; mas, estes tendiam a ver a problemática ambiental como um desvio das questões cruciais do humanismo.

Buttel (1992), por sua vez, assinala o relacionamento ambíguo da sociologia, em sua fase de construção, com as ciências naturais. Se, de um lado, o pensamento sociológico foi influenciado por conceitos provenientes das ciências naturais, por outro lado, a própria necessidade de legitimação das ciências sociais exigiu uma reação contra a simplificação das explicações oriundas do determinismo biológico e geográfico, conforme mencionado anteriormente.

Foi neste contexto, embora de forma diferenciada, principalmente a partir dos anos de 1960, que grupos de sociólogos começaram a dar importância à problemática ambiental e perceber sua relevância e abrangência, passando a ocupar a agenda dos governos, organismos internacionais, movimentos sociais e setores empresariais em todo o mundo. Tornou-se evidente que a questão ambiental não era apenas mais um modismo passageiro e a sociologia ambiental assumiu desde então uma posição significativa para estudar as divergências e conflitos sobre a natureza e as causas e a extensão dos problemas ambientais (BUTTEL, 1987; REDCLIFT e WOODGATE; HANNINGAN, 1997; CATTON e DUNLAP, 1998).

Segundo Buttel (2000), a sociologia ambiental norte-americana, por exemplo, que dominou internacionalmente o sub campo até o fim dos anos de 1980 e início dos de 1990, tem tido algumas deficiências. A teoria sociológica ambiental norte-americana desenvolveu-se originalmente em reação à falta de atenção da sociologia dominante com os fenômenos biofísicos; assim, enfatizou tendências fortes, senão intrínsecas, das sociedades modernas à degradação do ambiente, e tendeu a minimizar a teorização dos 
COSTA FERREIRA, L. da. Idéias para uma sociologia da questão ambiental...

processos de melhoramento ambiental. Mas, de certa forma incoerentemente, a sociologia ambiental dominante também se inclinou a ver que estas tendências à degradação ambiental poderiam ser revertidas se a mobilização ambientalista unisse forças suficientes, fazendo dela uma força progressiva sui generis. ${ }^{l}$

A cultura sociológica ambiental norte americana tendeu, assim, a simplificar os processos de mobilização ambientalista e a exagerar a coerência do ambientalismo. Finalmente, ressalta o autor, os principais trabalhos da sociologia ambiental norte-americana tenderam a uma visão reducionista da política ambiental, seja vendo a formação das políticas estatais ambientais em termos relativamente benignos, seja enfatizando as forças inexoráveis que compelem a política estatal a exacerbar a degradação ambiental.

Buttel (2000) comenta algumas tendências recentes na cultura sociológica ambiental - particularmente o despontar das teorias sobre a pós-modernidade no seio da cultura sociológica geral, e a aplicação de uma perspectiva particular da pós-modernidade (modernização reflexiva) aos problemas da relação entre sociedade e ambiente. Para o autor a teoria de Beck (1992) sobre a sociedade de risco e os trabalhos de Spaargaren (1996) e Mol (1995) são as contribuições mais visíveis para a sociologia ambiental ancoradas na noção de modernização reflexiva. Em acréscimo, teóricos sócio-construtivistas e analíticos do discurso, tais como Hannigan (1997) e Yearley (1996) têm apresentado sociologias interpretativas dos riscos ambientais e da política ambiental que são largamente consistentes com o quadro de referência da modernização reflexiva.

\section{O clima intelectual e a trajetória político-institucional}

O processo de institucionalização da sociologia ambiental no interior da sociologia certamente não foi homogêneo. Pode ser subdividido em função dos acontecimentos políticos e culturais do momento, assim como do próprio desenvolvimento intelectual do estado da arte. Assim, por um lado, podemos distinguir núcleos dinâmicos de ensino, pesquisa e debate em diversos locais do mundo, inclusive no Brasil. Às vezes este núcleo dinâmico consiste de alguns professores, ou apenas um sociólogo, que lida com a questão ambiental; outras vezes, é todo um conjunto no qual se incluem departamentos, professores nacionais e estrangeiros, o debate científico, o ensino de teorias e técnicas, a realização de pesquisas.

A trajetória político-institucional da subdisciplina nos Estados Unidos iniciou-se na década de 1970. Cabe ressaltar que já nos anos de 1960, havia uma produção não-sistemática, mas interessante, que abordava a problemática a partir de uma perspectiva mais radical, tanto nos Estados Unidos, como na Europa. De fato, todo o período que engloba os anos de 1960 até meados de 1980 foi profundamente influenciado pelo clima cultural dos anos 1960: os novos movimentos sociais, a contra-cultura, a crítica radical ao industrialismo e ao armamentismo marcaram uma mudança drástica no clima cultural e universitário em várias partes do planeta, inclusive nos Estados Unidos, acentuando a necessidade de se investigar a problemática ambiental.

A preocupação inicial concentrou-se nos aspectos conservacionistas da questão ambiental, mas, gradualmente, foi ganhando novos contornos; nos anos de 1960, através da crescente preocupação com a contaminação ambiental produzida pela produção industrial e agrícola (CARSON, 1962) e, a partir de 1973, através da crise energética deflagrada pela alta dos preços do petróleo. Essa crise energética coincidiu com o lançamento, pelo Clube de Roma, do Relatório Limites do Crescimento (MEADows, 1972), que alertava de forma tempestuosa a possibilidade do esgotamento dos recursos naturais e de uma catástrofe ambiental planetária, caso se mantivessem constantes as expectativas de crescimento econômico (PAEHLKE, 1989; MAC CORMICK, 1992; ECKERSLEY, 1995). ${ }^{2}$ A publicação do relatório acarretou intensos debates sobre a questão da escassez e do modelo de crescimento vigente (OPHULS, 1973), apesar das inúmeras críticas recebidas. Nesse período, houve uma proliferação de iniciativas de pesquisas sobre a mobilização política ambientalista (GALTUNG, 1984; MAC CORMICK, 1992); impactos da produção, consumo e desperdício de energia em específico (LOVINS, 1977; NEMETZ, 1982) e de recursos

1 Comentários sobre o impacto dessas simplificações na constituição e rumos do ambientalismo brasileiro ver Ferreira, 1999.

2 Para uma análise deste período ver Ferreira, 1992. 
COSTA FERREIRA, L. da. Idéias para uma sociologia da questão ambiental...

naturais de um modo geral (BROwN, 1986); análises de políticas ambientais (GORZ, 1980; HAYS, 1982; PAEHLKE, 1989); de alternativas tecnológicas de crescimento (DICKSON, 1974); além do debate acirrado e polêmico sobre a questão populacional (EHRLICH, 1975). ${ }^{3}$

Em paralelo, a seção de sociologia ambiental da American Sociological Association cresceu de 290 membros em 1976 para 321 em 1979, atraindo pesquisadores com diferentes interesses na área. Segundo Dunlap (1997), em meados da década de 1970, as três associações nacionais de sociologia nos Estados Unidos (Rural Sociological Association, Society for the Study of Social Problems, além da American Sociological Association) iniciaram grupos e seções de sociologia ambiental, além do tema ter sido tratado em várias outras seções.

Ainda de acordo com Dunlap, a problemática da escassez dos recursos naturais, apesar de bastante divulgada e debatida, não foi devidamente assimilada pela cultura política norte-americana, orientada pelo mito do crescimento ilimitado. Nesse sentido, a era Reagan representou a rejeição explícita à idéia de limites, e a promessa do sonho norte-americano de crescimento e prosperidade interrompeu o pesadelo da escassez (VIG e KRAFT, 1992). Obviamente este processo interferiu na produção da área, que segundo Dunlap (1997), sofreu um declínio na década de 1980. Conforme o autor, a seção de sociologia ambiental teve uma redução para menos de 300 membros em 1980; poucos artigos novos foram escritos e nenhum deles foi publicado nos principais periódicos de sociologia.

Contudo, os grandes acidentes envolvendo usinas nucleares e contaminações tóxicas de grandes proporções, como os casos de Three-Mile Island (1979), Love Canal, Bhopal (1984) e Chernobyl (1986), acirraram novamente o debate público e científico sobre a questão dos riscos nas sociedades contemporâneas; conseqüentemente, a questão da cidadania e da qualidade de vida ganhou novos impulsos naquele momento (DUNLAP, 1997; HOGAN e VIEIRA, 1992). Iniciou-se, nesse período, uma mudança de escala na análise dos problemas ambientais, que passavam de um nível local para o global, transformando igualmente a freqüência de problemas e acidentes ambientais. A própria natureza dos problemas tornava-os mais difíceis de serem previstos e compreendidos (DUNLAP, 1993; FERREIRA e VIOLA, 1996).
Na verdade, em fins dos anos de 1980 assistiu-se no cenário internacional a um clima favorável ao processo de consolidação da área no nível internacional. Vários dados comprovam esta afirmação: novamente pôde-se observar um aumento do número de membros na seção da ASA na virada da década, atingindo 400 membros em 1993. O volume de textos publicados e o crescente interesse de estudantes nos cursos voltados à problemática também confirmaram essa retomada. Outro sintoma significativo foi o aumento da atenção internacional dedicada à área, e a formação de um grupo de trabalho sobre ambiente e sociedade em 1990, na Associação Internacional de Sociologia (ISA), sem mencionar o impacto da Rio-92 (DUNLAP, 1997).

No que diz respeito à perspectiva constitutiva dos aspectos teórico-metodológicos, Buttel (1996) comenta que a trajetória da sociologia ambiental poderia ser sintetizada em três momentos distintos: o momento de formação, a partir da combinação e contribuição de outras sociologias específicas; a fase de constituição de um núcleo teórico próprio e de perfil mais consensual; e um momento de diversificação e maior incorporação no campo teórico da sociologia em geral.

Com relação ao período de formação, o autor comenta que a sociologia rural foi pioneira na contribuição para a área, embora outras sociologias específicas tenham participado desse processo: a sociologia de comunidades, do desenvolvimento, a sociologia urbana e a dos movimentos sociais. Em certa medida, a sociologia ambiental não surgiu como uma nova disciplina, mas dentro das disciplinas já existentes, tentou cobrir a lacuna teórica da tradição clássica frente às questões ambientais, criando um locus institucional para o desenvolvimento da nova temática.

No tocante à lacuna teórica, Buttel (1996) considera que a tendência da sociologia clássica foi criar teorias que, implicitamente, assumissem que as sociedades e grupos humanos são independentes ou isolados dos processos biofísicos. Para ele, a sociologia, em busca de liberar o pensamento social dos reducionismos, preconceitos e da visão conservadora do início da ecologia humana, exagerou ao promover a separação entre o processo social e o mundo natural. Catton e Dunlap (1998) são mais enfáticos na crítica à resistência da sociologia às questões ambientais, salientando o contexto sociocultural da formação da sociologia, assim como seus paradigmas de análise. Argumen- 
COSTA FERREIRA, L. da. Idéias para uma sociologia da questão ambiental...

tam que a sociologia foi profundamente influenciada por uma cultura ocidental antropocêntrica. Essa visão de mundo, por sua vez, foi historicamente acentuada por processos convergentes de desenvolvimento técnico-científico e acumulação de riquezas, propiciada pela expansão colonial, que resultou na revolução industrial, no fortalecimento de idéia de progresso e no processo de ocidentalização do mundo.

A fase seguinte, de constituição de um núcleo teórico, unificou-se em torno da produção de alguns sociólogos ambientais como Catton, Dunlap, Schnaiberg, Buttel, Redclift, Harteley, Chapman, Yearley, Hannigan, dentre outros, que mais se destacaram na produção teórica após os anos de 1970. Esses autores, apesar das diferenças de suas perspectivas de análise, enfatizavam o caráter materialista e realista da crise ambiental, sem deixar de lado a importância de sua dimensão cultural. Criticaram fortemente a insustentabilidade das sociedades modernas, por se apoiarem em um modelo de produção, consumo e descarte que dilapidou os recursos naturais muito mais rapidamente que sua capacidade de regeneração.

O terceiro momento na trajetória intelectual da sociologia ambiental, mais nítido na virada da década de 1980 , caracterizou-se por uma maior diversidade teórica e por certa incorporação da teoria sociológica clássica. Destacaram-se, em primeiro lugar, as influências advindas da sociologia contemporânea, no sentido de uma guinada cultural que reduz a ênfase nas explicações materialistas e estruturalistas em favor de perspectivas culturais, subjetivas e com forte influência da sociologia do cotidiano. Essa mudança teórica contribuiu fortemente para um aumento na receptividade da questão como fenômeno social relevante. É possível registrar, a partir desse momento, as contribuições de sociólogos de destaque, que enfatizam a importância da questão no contexto das sociedades da alta modernidade, como é o caso de Beck (1992), Giddens (1991), Touraine (1989), Castells (1999), Habermas (1987) dentre outros.

A nova perspectiva de análise, para Hannigan (1997), por exemplo, passou a enfatizar os processos sociais, políticos e culturais, em que as condições ambientais são definidas como aceitáveis ou não. Neste sentido, um problema ambiental é socialmente construído, aspecto percebido como mais relevante do que a própria tarefa de avaliar suas condições de validade. Os problemas ambientais seriam similares aos demais problemas sociais e a ação dos diferentes atores seria o objeto principal de análise.

\section{Teoria social e ambiente}

Este item explora a contribuição de alguns teóricos sociais contemporâneos a duas questões: as origens e os efeitos da degradação do ambiente nas sociedades modernas, e as condições sob as quais as forças políticas podem ser mobilizadas com êxito contra a degradação do ambiente. Relativamente à primeira questão, é quase polêmico afirmar que as transformações de ordem econômica e demográfica são causas relevantes de degradação do ambiente. Contudo, vale a pena examinar, com mais atenção do que por vezes presta-se os mecanismos exatos que estas forças põem em movimento. Cabe examinar também o duplo papel do poder político e cultural ao favorecer a degradação do ambiente. A emergência dos movimentos políticos que tentam impedir a destruição do ambiente é um dos efeitos mais significativos da atual degradação do ambiente.

Tento refletir sobre estas questões através de um estudo de três sociólogos contemporâneos: Anthony Giddens, Jürgen Habermas e Ulrick Beck.

No caso de Giddens (1991; 1992; 1995; 2000) este tenta integrar a explicação das origens e efeitos da degradação do ambiente numa interpretação mais alargada do desenvolvimento e da dinâmica das sociedades modernas. Existe, todavia, outro motivo para se analisar como Giddens tem pensado a problemática ambiental. O primeiro motivo consiste no fato de sua explicação para a degradação do ambiente se centralizar na interação entre o capitalismo e o industrialismo. Em segundo lugar, a teoria social de Giddens prestou particular atenção à dimensão espacial dos processos sociais e dos métodos da geografia. Este fato permitiulhe investigar a natureza sociológica do urbanismo e da globalização e o modo como esta contribui para os problemas do ambiente. Em terceiro lugar, a abordagem interpretativa de Giddens à teoria social e os modelos multicausais de processos sociais que este desenvolveu permitiram-me incluir a contribuição prestada pelo poder político e pelas atitudes culturais para a proliferação da degradação do ambiente. Finalmente, Giddens inclui na sua teoria social mais vasta uma explicação das origens dos movimentos sociais ambientalistas. Deste modo, a sua obra permitenos apreciar o duplo atributo do poder político e cultural: ambos podem ajudar e controlar o processo de degradação do ambiente.

No que diz respeito a Habermas (1987), em primeiro lugar, a sua obra recente proporcionou uma das mais 
COSTA FERREIRA, L. da. Idéias para uma sociologia da questão ambiental...

profundas reavaliações da teoria social clássica e, ao fazêlo, produziu a re-interpretação mais completa tanto da organização institucional da modernidade como da sua evolução cultural. Em segundo lugar, Habermas utilizou esta estrutura para investigar a emergência de novos movimentos sociais e para avaliar a potencial importância política desses movimentos. Em terceiro lugar, o autor permiti-nos examinar os meios pelos quais a mudança das estruturas sociais deu origem a uma nova organização de interesses econômicos e políticos, e o modo como estes interesses moldam, por sua vez, a mobilização das políticas contemporâneas de meio ambiente. Em quarto lugar, Habermas permiti-nos examinar a forma como surgiram as transformações culturais e os conhecimentos morais modernos sobre o ambiente, como estes redefiniram interesses e contribuíram para a emergência de movimentos políticos orientados para as questões de ambiente. Por último, ao acompanhar a abordagem interdisciplinar, a obra de Habermas recorre e esforça-se por reunir algumas das observações mais importantes de cientistas políticos, que investigam as origens estruturais da política de ambiente.

Chegamos, por fim, à obra de Ulrick Beck (1992; 1997). O que distingue verdadeiramente a obra de Beck entre todos os teóricos sociais contemporâneos é o fato de o potencial catastrófico da degradação do ambiente no nível global ocupar a cena principal. Beck vai mesmo ao ponto ao afirmar que a modernidade descrita nas obras dos teóricos sociais clássicos está a sendo transformada num tipo de sociedade fundamentalmente diferente - uma sociedade de risco. Essa transformação é, em parte, movida pela emergência de níveis profundos e historicamente incompatíveis de perigos e riscos para o ambiente que atingem uma dimensão e forma tais que os modelos convencionais da sociedade moderna não conseguem apreender as suas origens e conseqüências. Os argumentos de Beck relativamente à transformação da modernidade clássica numa sociedade de risco são rigorosamente confrontados com o modelo de Giddens de modernidade tardia radicalizada, no qual os movimentos sociais ambientalistas reagem a riscos e perigos para o ambiente recentemente observados. Beck investiga também os meios pelos quais as relações do poder político e cultural contemporâneo servem para ocultar as origens da degradação do ambiente e proteger os perpetradores dessa degradação. Finalmente, Beck, tal como Habermas, defende que a democracia e a democratização tanto do processo político convencional como dos centros de decisão econômica, previamente despolitizados, constituem um elemento essencial de uma política de ambiente sustentada.

\section{A questão ambiental e as ciências sociais no Brasil: rumo à interdisciplinaridade}

No Brasil, as tentativas de institucionalização do campo de conhecimento que trata das relações entre sociedade e natureza/ambiente iniciaram-se em meados da década de 1980 e as primeiras iniciativas aconteceram na região sudeste, com ênfase especial para a Universidade Estadual de Campinas e Universidade de São Paulo, no estado de São Paulo e Universidade Federal de Santa Catarina.

Os re-arranjos científico, intelectual e institucional propostos não eram novos e de certa maneira espelhavam clivagens produzidas no período posterior à $2^{\mathrm{a}}$ Guerra Mundial em outras partes do mundo, em torno dos debates quanto aos estudos interdisciplinares (FERREIRA, 2000). O grupo que liderava os debates na Unicamp decidiu espelhar-se nos estudos por áreas ou regiões e, através de forte base empírica, agregar cientistas sociais e cientistas naturais que se debruçariam por regiões dotadas de suposta coerência cultural e histórica, com o objetivo de descrever-lhes sob um ponto de vista multidimensional. Como esses estudos eram, por definição, multidisciplinares, criou-se um centro de pesquisas ${ }^{4}$ e a formação continuava delimitada aos programas tradicionais de graduação e Pós-Graduação, onde foram criadas linhas de pesquisa transversais às especialidades de origem, de modo a tratar da questão ambiental.

Na USP, o grupo que se organizou em torno da questão ambiental em meados da década de 1980 vinha de outra filiação, pois era fortemente influenciado pelos teóricos da ecologia profunda e da complexidade (PRIGOGINE e STENGERS, 1991; PRIGOGINE, 1996; MATURANA e VARELA, 1994; SESSIONS, 1995). Em busca de um paradigma holista criaram um curso de Mestrado em Ciência Ambiental, que apesar das reformulações que sofreu no futuro, teve o mérito de colocar a nu a artificialidade das rígidas clivagens institucionais anteriores.

Em Santa Catarina pode-se observar uma agregação de interesses em torno do paradigma da ecologia política, 
COSTA FERREIRA, L. da. Idéias para uma sociologia da questão ambiental...

que cruzava uma abordagem teórica da sociologia e da política de forte tradição sistêmica com preocupações em alargar o objeto de estudo em direção às múltiplas dimensões da interação entre a biosfera e uma sociedade globalizada.

Apesar dos avanços e recuos, apesar ainda da forte resistência do núcleo duro das ciências sociais brasileiras em dialogar com esta produção intelectual, pode-se afirmar que os estudos e pesquisas interdisciplinares atuais herdaram deste período uma evolução significativa da situação social ocorrida no interior das instituições de ensino e pesquisa, e dos quadros por elas formados. Se não se abandonou a estrutura departamental, os próprios departamentos hoje não têm como negar a validade e legitimidade das experiências interdisciplinares de alguns de seus membros.

Assim, talvez seja possível afirmar que as ciências sociais que têm trabalhado com a questão ambiental no Brasil, encontra-se em fase intermediária, quando comparada às experiências internacionais. Menos pelo impacto da produção e mais pela resistência que ainda enfrenta por parte de setores fortemente disciplinares das ciências sociais brasileiras.

O melhor exemplo do grau e do tipo de organização da área pode ser analisado através da trajetória do Grupo de Trabalho Ecologia, Política e Sociedade da Associação Nacional de Pós Graduação e Pesquisa em Ciências Sociais (Anpocs) (VIEIRA, 1992; FERREIRA e VIOLA, 1996; DRUMOND e SCHOROEDER, 1998, FERREIRA, 2000; FERREIRA, e FERREIRA, 2002 e ALONSO e COSTA, 2002), que se desenrolou em paralelo à mobilização das três universidades pioneiras em torno da questão ambiental. Além disso, talvez pelo pioneirismo, o GT organizado em torno da Anpocs revestiu-se de grande liderança na constituição do subcampo das ciências sociais do ambiente no Brasil, funcionando como forte agregador de demandas intelectuais produzidas por grupos isolados que emergiam em diversos cantos do país.

Este grupo reuniu-se pela primeira vez na Anpocs em 1986, quando a problemática ambiental ainda era tratada de forma incipiente nas ciências sociais brasileiras e reunia apenas um pequeno grupo de intelectuais. Desde então, a questão ambiental adquiriu relevância na comunidade científica mundial, como vimos anteriormente e isso se refletiu na comunidade científica local como veremos no desenrolar deste artigo.

Desde então, vários intelectuais ligados ao grupo partiram para o exterior para fazer Doutorado, Pós-Douto- rado, além de intercâmbio de grupos de pesquisa, preferencialmente, mas não exclusivamente, nos Estados Unidos, França e Inglaterra. Esse processo refletiu-se intensamente na produção da área, pois propiciou o cruzamento fecundo de dados e modelos teóricos, engatando definitivamente a produção local ao debate internacional.

Em paralelo a esta busca de diálogo com os setores mais fortemente institucionalizados das ciências sociais brasileiras, ainda na primeira metade dos anos de 1990 houve uma intensa mobilização dos cientistas sociais para fortalecer institucionalmente o diálogo, o ensino e a pesquisa interdisciplinar, participando da criação de centros de pesquisa e programas de Pós-Graduação em torno do campo de conhecimento que trata da interação entre sistemas biofísicos e sociais. Possivelmente essa disseminação do interesse em montar uma burocracia adequada aos estudos, pesquisas e formação na área ambiental se deva aos dois condicionantes já levantados: 1) no âmbito da sociedade, o clima político propício produzido pela Rio-92 e, 2) no âmbito acadêmico, a boa receptividade encontrada pelos brasileiros no debate internacional, resultado do intenso intercâmbio com centros especializados e importantes fora do país.

Hoje, a sociologia ambiental, as ciências políticas do ambiente, os estudos antropológicos e populacionais sobre o tema já se encontram consolidados em várias universidades brasileiras, sendo que a produção de dissertações, teses e o volume de livros e trabalhos publicados (FERREIRA e FERREIRA, 2002) reflete o grau de interesse que esta problemática adquiriu.

Além disso, existem outros indicadores do grau de institucionalização da temática no país. Vale mencionar a publicação da revista Ambiente \& Sociedade, uma co-edição das três universidades pioneiras na institucionalização desse campo de estudos e pesquisas, a Unicamp, a USP e a UFSC, o periódico vem se consolidando como uma publicação temática, cujo objetivo é promover o escoamento da produção de cientistas sociais com características transversais às suas especialidades de origem. O periódico é financiado pela Fundação de Amparo à Pesquisa do Estado de São Paulo (Fapesp) e pelo Conselho Nacional de Pesquisa (CNPq), além de estar na Scielo.

Outro indicador que merece menção foi a centralidade da temática ambiental em alguns dos mais importantes congressos das ciências sociais do país, como o da Associação de Antropologia (ABA) no ano de 2000 e do Congresso Internacional de Sociologia Rural que foi realizado no Rio 
COSTA FERREIRA, L. da. Idéias para uma sociologia da questão ambiental...

de Janeiro do mesmo ano. Vale mencionar que em paralelo ao Congresso de Sociologia Rural ocorreu o Simpósio Sociological Reflections on Sustainability, do Committee on Environment and Society da ISA.

Curiosamente, à medida que foram sendo estreitados o diálogo e a colaboração entre a sociologia ambiental brasileira e a internacional, ou entre esta e outras disciplinas das ciências sociais no Brasil; à medida em que foi montando seu próprio sistema institucional, à semelhança do que ocorreu ao grupo da ASA nos Estados Unidos no início da década de 1980, a Anpocs deixou de abrigar o Grupo de Trabalho originalmente organizado em torno da temática ambiental. Desde o final dos anos de 1990 alguns de seus membros têm sido estimulados pela direção da associação a promover fóruns e mesas redondas nessa linha, como forma paliativa de referendar a importância deste debate intelectual e desta produção científica.

Esse inesperado desinteresse do núcleo mais fortemente institucionalizado das ciências sociais brasileiras não significou um declínio do interesse pela área e os intelectuais e estudantes ligados originalmente ao GT da Anpocs direcionaram seu poder de influência em três outras direções: 1) escoamento de sua produção através de outros fóruns acadêmicos nacionais, como a Sociedade Brasileira de Sociologia (SBS), a Sociedade Brasileira de Antropologia, a Associação Brasileira de Sociologia Rural, dentre tantos outros de grande importância; 2) investimento no diálogo internacional, através da participação em eventos como, por exemplo, da Latin American Studies Association (Lasa) e da Internacional Sociological Association (ISA), para citar apenas dois; e finalmente, 3) investimento em veículos próprios, como a Revista Ambiente \& Sociedade, além da Associação Nacional de Pós Graduação e Pesquisa em Ambiente e Sociedade (Anppas), cujo primeiro congresso de âmbito nacional foi realizado no final de $2002 \mathrm{e}$ o segundo no primeiro semestre de 2004.

Além disso, cabe ressaltar que na Anpocs de 2004, a temática está presente em dois seminários temáticos; sobre Ambiente e Natureza e sobre a interface entre as Ciências Sociais e as Ciências Biológicas.

\section{A produção intelectual brasileira}

Há dois momentos na produção intelectual brasileira que delineiam os rumos das agregações de demandas intelectuais no campo das interações entre Ambiente e Socie- dade no Brasil. No primeiro deles, em uma fase que pode ser considerada sob a inspiração de Buttel (1996) como de formação, há quatro coletâneas que merecem destaque. Inaugurando os debates do campo, indiscutivelmente temse o livro Ecologia e Política no Brasil (1987), organizado por José Augusto Pádua. Se não foi o primeiro lançamento, esta coletânea agregou a legitimidade política e acadêmica do editor à capacidade de delinear de forma clara e inteligível ao público leigo o tema das relações entre Ecologia e Política. Reúne textos apresentados durante um seminário realizado no Rio de Janeiro em 1985, momento em que se iniciava a discussão no país da criação do Partido Verde.

Além disso, ressalta-se aqui o fato da temática já ser trabalhada de forma sistemática em outros grupos como, por exemplo, observa-se o artigo de Guimarães (1984).

A coletânea Ecologia e Política Mundial (1991), organizada por Héctor Leis foi produto da Área Ambiental do Instituto de Relações Internacionais da Pontifícia Universidade Católica do Rio de Janeiro, conjuntamente com a área de publicações da Federação de Órgãos para Assistência Social e Educacional (Fase). Era parte de um ambicioso programa editorial que pretendia vincular e comprometer esforços de instituições acadêmicas, organizações não governamentais e editoras, a fim de realizar uma reflexão crítica sobre o que seus autores denominavam de "emergente espaço público transnacional do ecologismo". Conscientemente desejava servir de ponte tanto no sentido Sul Sul como Sul - Norte, ampliando e estendendo as redes de cooperação entre indivíduos, organizações e países.

Em face da perspectiva de realização da Conferência das Nações Unidas sobre Meio Ambiente e Desenvolvimento (CNUMAD) no Rio de Janeiro em junho de 1992, o antigo grupo de trabalho Ecologia, Politica e Sociedade da Anpocs, desta vez liderado pelo grupo da Unicamp, de forte orientação empírica, optou por abrir um espaço prioritário de discussões, visando o aprofundamento crítico dessa temática, referenciando-a ao contexto brasileiro.

À medida que a pauta oficial das discussões e resoluções da CNUMAD contemplava fundamentalmente problemas ambientais de natureza global, como efeito estufa, alterações na camada de ozônio, poluição dos mares, perda da biodiversidade, a preocupação dos membros do grupo foi dupla. Por um lado, constatou-se que tais problemas tendem a ser veiculados junto à opinião pública como desafios que se colocam acima das especificidades socioculturais, econômicas e político institucionais de cada nação. 
COSTA FERREIRA, L. da. Idéias para uma sociologia da questão ambiental...

Por outro lado, privilegiando a questão amazônica, os promotores do Encontro pareciam subestimar o fato óbvio que $90 \%$ da população brasileira está atualmente concentrada em outras regiões do país, sob o processo devastador de urbanização acelerada. A mobilização da opinião pública durante os meses que antecediam a Conferência corria o risco de camuflar a contundência daqueles problemas socioambientais mais diretamente relacionados à garantia do direito à qualidade de vida dos brasileiros. De forma contraditória, a Conferência poderia vir a se constituir um retrocesso político, no processo de lutas pela construção de uma política ambiental melhor ajustada às características brasileiras. Assim, a opção editorial refletiu o perfil acadêmico das ciências sociais ambientais brasileiras e as formas de abordagem de alguns dos nossos desafios socioambientais, resgatando da melhor maneira possível, a ampla diversidade regional e temática envolvida.

Apesar da pluralidade de referências teóricas e enfoques metodológicos subjacentes ao conjunto das contribuições do livro Dilemas Socioambientais e Desenvolvimento Sustentável (1992), organizado por Daniel Hogan e Paulo Vieira, podemos observar uma preocupação comum em relacionar os sistemas sociais aos naturais e também em explicar a especificidade dos problemas socioambientais dos países em desenvolvimento.

O Livro Incertezas de Sustentabilidade na Globalização (1996), organizado por Leila Ferreira e Eduardo Viola, partia de uma premissa: a existência de processos globais que transcendem às categorias Estado, classe social e nação. Sua hipótese era a emergência de uma sociedade global. Segundo os organizadores, o objeto de estudo do livro seria a biosfera, que necessariamente ultrapassa as fronteiras nacionais. A preocupação ecológica não tem pátria, seu enraizamento é o planeta.

Seria esperado que uma reflexão sobre globalização e ambiente se afastasse das particularidades. No caso deste livro um dos fios condutores das preocupações dos autores revelava-se exatamente através do cotidiano. Além das discussões mais gerais sobre globalização, há um conjunto de problemas muito familiares ao GT, como a consolidação da democracia no Brasil, o poder local, a problemática da águas, dos diferentes tipos de poluição, a questão da qualidade de vida, a questão do espaço público, a discussão sobre desenvolvimento das áreas protegidas.

Já no início da primeira década do novo século podemos observar uma mudança significativa dos interesses deste núcleo mais fortemente agregado em torno do campo de reflexões sobre a interface entre sociedade e ambiente. Um bom indicador deste desvio na ênfase pode ser buscado na agregação de demandas intelectuais impostas à Anppas. A programação de seus dois primeiros encontros delineiam os seguintes temas para debates no âmbito dos GTs e mesas redondas: regimes ambientais internacionais, dimensões humanas da biodiversidade; consumo e segurança alimentar e de energia, dimensões locais das mudanças ambientais, cidades sustentáveis, educação ambiental em sociedades do conhecimento, além dos já tradicionais, como interdisciplinaridade, dinâmicas demográficas, risco ambiental e políticas ambientais e teoria e meio ambiente.

Podemos aqui já arriscar algumas conclusões da análise da produção na área de Ambiente e Sociedade. Em primeiro lugar, esta produção específica é de difícil avaliação apesar de sua pujança e visibilidade social nos últimos anos, pois justamente por se debruçar sobre questões relativas a novas orientações normativas da sociedade contemporânea, sua literatura muitas vezes padece de excesso de normatividade, em detrimento das abordagens analíticas ou interpretativas.

Por outro lado, podemos observar que a produção intelectual no Brasil teve também forte influência da teoria social contemporânea e mais recentemente da sociologia ambiental como podemos observar nos artigos publicados nas principais revistas de ciências sociais no Brasil.

$\mathrm{Na}$ verdade citaremos aqui seis revistas nacionais, quais sejam: Revista Brasileira de Ciências Sociais, onde obtivemos desde 1986 um total de 8 artigos diretamente relacionados ao tema; a revista Lua Nova, onde encontramos no mesmo período 9 artigos. Na revista Dados podemos observar a publicação de 5 artigos e na revista São Paulo em Perspectiva um total de 9 artigos. Na revista Tempo Social encontramos somente 3 artigos correlacionados com a área. Por sua vez analisamos detalhadamente a revista Ambiente\&Sociedade exatamente por entendermos que ela congrega a principal produção da área no Brasil.

Podemos concluir, portanto, que houve uma real internalização da questão ambiental nas ciências sociais brasileiras, apesar, que numericamente os artigos produzidos nos periódicos citados anteriormente não sejam muito significativos, a análise dos programas de Pós-Graduação na área (FERREIRA e FERREIRA, 2002), assim como os livros publicados no Brasil sobre o tema são significativos. 
COSTA FERREIRA, L. da. Idéias para uma sociologia da questão ambiental...

\section{REFER $\hat{E} N C I A S$}

ALONSO, A; COSTA, V. Ciências Sociais e Meio Ambiente no Brasil: um balanço bibliográfico. Anpocs bib. Revista Brasileira de Informação Bibliográfica em Ciências Sociais, $\mathrm{n}$. 53, 2002.

BECK, U. Risk Society. Towards a New Modernity. London: Sage Publications, 1992.

The Reinvention of Politics. Rethinking Modernity in the Global Social Order. Polity Press.Cambrigde, 1999.

BOURDIEU, P. Economia das trocas simbólicas. São Paulo: Perspectiva, 1980.

BROWN, L.. State of the world. New York: W.W. Norton, 1986.

BUTTEL, F. New directions in environmental sociology. Annual Review Sociology, n. 13, p. 465-488, 1987.

.A sociologia e o meio ambiente: um caminho tortuoso rumo à ecologia humana. Revista de Ciências Sociais, São Paulo: Unesp, v. 15, p. 69-94, 1992.

Environmental and resource sociology: theoretical issues and opportunities for synthesis. Rural Sociology Society, Institute for Environmental Studies. University of Illinois, v. 61, n. 1, 1996.

Sociologia ambiental, qualidade ambiental e qualidade de vida: algumas observações teóricas. In: HERCULANO, S.; PORTO, M.; FREITAS, C. (Org.). Qualidade de vida e riscos ambientais. Niterói: EDUFF, 2000.

CARSON, R. Silent spring. Boston: Houghton Mifflin, 1962.

CASTELLS, M. A sociedade em rede. Rio de Janeiro: Paz e Terra, 1999.

CATTON, W.; DUNLAP, R. Environmental sociology: a new paradigm. The American Sociologist, Washington, D. C., v.13, n. 1, Feb. 1998.

COMISSÃO GULBENKIAN. Para abrir as ciências sociais. São Paulo: Cortez, 1996.

DUNLAP, R. From Environmental to Ecological Problems. In: CALHOUN, C.; RITZER, G. (Org.). Social Problems. New York: MacGraw-Hill, 1993.

The evolution of environmental sociology: a brief history and assessment of American experience. In: REDCLIFT, M.; WOODGATE, G. (Eds.). The International
Handbook of the environmental sociology. Northampton. Madison, 1997.

DURKHEIM, E. Select Writings. Cambridge: Cambridge University Press, 1995.

ECKERSLEY, R. Environmentalism and political theory. 3. reimp. London: UCL Press, 1995.

EHRLICH, P. The population bomb. Massachussets: Riversity Press, 1975.

FERREIRA, Leila da C. A questão ambiental: políticas públicas no Brasil. São Paulo: Boitempo, 1998.

. Estado e ecologia: novos dilemas e desafios. (A política ambiental no Estado de São Paulo). Campinas, 1992. Tese (Doutorado) - IFCH, Unicamp.

. (Org.). A sociologia no horizonte do século XXI. São Paulo: Boitempo, 1997.

.; VIOLA, E. (Orgs.). Incertezas de sustentabilidade na globalização. Campinas: Unicamp, 1996.

FERREIRA, Leila; FERREIRA, Lúcia. Águas revoltas: um balanço provisório da sociologia ambiental no Brasil. Anpocs bib. Revista Brasileira de Informação bibliográfica, n. 54. São Paulo: Edusp, 2002.

FERREIRA, Lúcia da C. A importância da interdisciplinaridade para a sociedade. In: A interdisciplinaridade nas ciências ambientais. Brasília: Pnuma/MCT/PADCT-Ciamb, 2000.

Conflitos sociais contemporâneos: considerações sobre o ambientalismo brasileiro. Ambiente e Sociedade, n. 5, 1999.

FLORIANI, Dimas. Conhecimento, meio ambiente e globalização. Curitiba: Juruá, 2004.

GALTUNG, J. Los azules y los royos, los verdes y los pardos: una evolución de movimentos politicos alternativos. Boletim de Ciências Sociais. Florianópolis: FLP/ UFSC, n. 34, 1984.

GIDDENS, A. As conseqüências da modernidade. São Paulo: Universidade Estadual Paulista, 1991.

A transformação da intimidade: sexualidade, amor e erotismo nas sociedades modernas. São Paulo: Unesp, 1993.

Mundo em descontrole. Rio de Janeiro, São Paulo: Record, 2000. 
COSTA FERREIRA, L. da. Idéias para uma sociologia da questão ambiental...

GORZ, A. Ecology as politcs. Montreal: Black Rose Books, 1980.

GUIMARÃES, R. Eco-política em áreas urbanas: a dimensão política dos indicadores de qualidade ambiental: In: SOUZA, Amaury de. (Ed.). Qualidade de vida urbana. Rio de Janeiro: Zahar, 1984.

GUIVANT, J. Trajetórias das análises de risco: da periferia ao centro da teoria social. In: Anpocs bib. Revista Brasileira de Informação bibliográfica, n. 46, jul./dez. 1998.

HABERMAS, J. The Theory of Communicative Action, Boston: Beacon Press, v. 2, 1987.

A nova intransparência. Novos estudos Cebrap. São Paulo, 1987.

HANNIGAN, J. Environmental Sociology - a social constructionist perspective. New York, London: Routledge, 1997.

HAYS, S. P. From conservation to environment: environmental politcs in United States since World War Two. Environmental Review 6, p. 19-32, Fall 1982.

HOGAN, D.; VIEIRA, P. Dilemas socioambientais e desenvolvimento sustentável. Campinas: Unicamp, 1992.

Socio-demographic dimensions of sustainability. Brazilian perspectives. Rio de Janeiro: ISA, 2000.

LEIS, H. Ecologia e politica mundial. Rio de Janeiro: Vozes, 1991.

LOVINS, A. B. Soft energy paths. Massachusetts: Cambridge, 1977.

MARX, K. O capital. Crítica da economia política. Rio de Janeiro: Civilização Brasileira, 1980, v. 2.

MATURANA, H.; VARELA, F. El árbol del conocimiento. Santiago: Universitária, 1995.

MCCORMICK, J. Rumo ao paraíso. Rio de Janeiro: Relume Dumará, 1992.

MEADOWS, D. (Ed.). The limits to growth. Massachusetts: Riversity Press. 1872.

MOL, A.; SPARGAREN, G. Environment, modernity and risk society. International Sociology, v. 8, n. 4, p. 431-459, 1993.

NEMETZ, P. N. (Ed.). Energy policy: the global challenge. Montreal: Institute for Research in Public Policy, 1982.
OPHULS, W. Ecology and the politcs of scarcity: a prologue to a political theory of the stade state. San Francisco: Freeman, 1973.

ORTIZ, R. As ciências sociais e o trabalho intelectual. São Paulo: Olho D’Água, 2003.

PÁDUA, J. A. Ecologia e política no Brasil. Rio de Janeiro: Espaço e Tempo, 1987.

PAEHLKE. Environmentalism and the future of progressive politics. Yale: New Haven, 1989.

PRIGOGINI, I. O fim das certezas. Tempo e caos e as leis da natureza. São Paulo: Unesp, 1996.

.; STENGERS, I. A nova aliança. Metamorfose da ciência. Brasília: UnB, 1991.

REDCLIFT, M.; WOOGATE, G. (Eds.). The International Handbook of Environmental Sociology. Edwaed Elgar. Cheltenham, Uk. Northampton, MA, USA, 1997

ROSZAK, T. Persona planeta: hacia un nuevo paradigma ecológico. Barcelona: Kairós, 1977.

SESSIONS, G. (Ed.). Deep ecology for the twenty first century. Boston, London: Shambhala, 1995.

VIEIRA, P. A problemática ambiental e as ciências sociais no Brasil. In: HOGAN, D.; VIEIRA, P. Dilemas socioambientais e desenvolvimento sustentável. Campinas: Unicamp, 1992.

VIG, N.; KRAFT, M. (Eds.). Environmental Polic. In: HOGAN, D.; VIEIRA, P. Dilemas socioambientais e desenvolvimento sustentável. Campinas: Unicamp, 1992.

VIOLA, E.; LEIS, H. A evolução das políticas ambientais no Brasil (1971-1991). In: HOGAN, D.; VIEIRA, P. Dilemas socioambientais e desenvolvimento sustentável. Campinas: Unicamp, 1992.

Globalização, sustentabilidade e governabilidade democrática no Brasil. In: TRINDADE, A. A.; CASTRO, M. F. (Org.). A sociedade democrática no final do século. Brasília: Paralelo 15, 1997.

WEBER, M. Ensaios de sociologia. Rio de Janeiro: Zahar, 1982.

YEARLEY, S. Sociology, environmentalism and globalization. London: Sage, 1996. 